\title{
Synthesis and study of N-acetyl D-glucosamine triazole derivatives as effective low molecular weight gelators
}

Hari P. R. Mangunuru, Jayasudhan Reddy Yerabolou, Guijun Wang*

*Corresponding Author:

Guijun Wang

$\mathrm{PhD}$, Professor

Department of Chemistry and Biochemistry

Old Dominion University

4541 Hampton Boulevard

Norfolk, VA 23529-0126

Email: g1wang@odu.edu

Telephone: (757) 683-3781

Fax: (757) 683-4628 
Graphical Abstract:

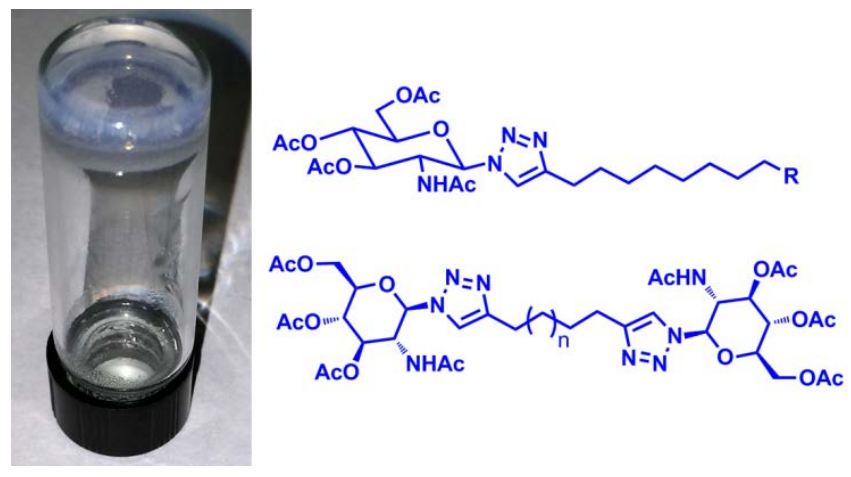




\begin{abstract}
:
Sugar based low molecular weight gelators have many potential uses for the formation of advanced soft materials. Here we have synthesized a series of peracetylated D-glucosamine triazole derivatives via the $\mathrm{Cu}$ catalyzed azide/alkyne cycloaddition reaction ( $\mathrm{CuAAc}$ ) and studied their self-assembling properties in several organic solvents, aqueous solutions, and water. Among the sixteen compounds synthesized and studied, many were able to function as organogelators for multiple solvents. Also seven compounds were able to form hydrogels at low concentrations such as $0.2-1.0 \mathrm{wt} \%$. These indicate that peracetylated D-glucosamine triazole analogs are effective small molecular gelators.
\end{abstract}

Keywords: Hydrogelator, glucosamine, triazoles, self-assembly, organogels 


\section{Introduction}

Low molecular weight gelators (LMWGs) or molecular gelators are an interesting class of compounds that are able to form reversible gels in organic solvents or aqueous solutions. ${ }^{1-4}$ Because gelation by LMWGs occurs mainly through non-covalent interactions, it may be possible to design certain chemical structures in which the non-covalent forces can lead to effective gelation of certain solvents. Intermolecular interactions, such as $\pi-\pi$ stacking, hydrogen bonding, and hydrophobic interactions can be modulated to obtain effective supramolecular structures that are able to entrap solvent molecules. The supramolecular gels formed by LMWGs especially hydrogels are interesting soft materials which may be utilized in many biomedical applications such as tissue engineering scaffolds and drug delivery vehicles. ${ }^{5-10}$ Therefore a great deal of effort has been devoted to finding new types of LMWGs and understanding the structure influences leading to gel formation. ${ }^{11-30}$

Among the many classes of compounds have been found to be able to gelate water or organic solvents, carbohydrate based systems are especially interesting since they can lead to biocompatible materials. ${ }^{24-30}$ In recent years, the $\mathrm{Cu}$ (I) catalyzed azide/alkyne cycloaddition reaction (CuAAc), the click reaction, has found important applications in many research areas such as in drug discovery, chemical biology, and materials chemistry. ${ }^{31-36}$ The formation of triazole by click chemistry has been used extensively in synthesizing glycoconjuates and glycomemitics. ${ }^{32-33}$ The triazole ring can participate in $\pi-\pi$ interactions and hydrogen bonding which may enhance or induce gelation. Many triazole containing compounds have been synthesized and studied over the past few decades, and several triazole based low molecular weight gelators have been reported. ${ }^{30,34-36}$ But, there is no systematic study on the gelation 
properties of $\mathrm{N}$-acetyl glucosamine derived triazole compounds yet. Previously, we have studied the functionalization of 4,6-benzylidene acetal protected monosaccharides and obtained effective sugar based LMWGs. ${ }^{25-28}$ We found that for D-glucose and D-glucosamine analogs with similar functionalizations, the glucosamine analogs are more effective in the gelation of a variety of polar solvents and water. Recently we have shown that peracetyled D-glucosyl triazoles are effective LMWGs for alcohols and aqueous mixtures of organic solvents, however they are not very effective for water alone. ${ }^{29}$ In this research, we synthesized a series of peracetylated glucosamine triazole analogues using the CuAAc click reaction, and analyzed their gelation properties in several organic solvents and aqueous mixtures.

\section{Results and Discussions}

As shown in Scheme 1, coupling of the peracetylated glucosamine azide 1 with various alkynes, a library of triazole derivatives can be obtained readily. The selection of the alkyne functional groups is based on their polarity and many of them are analogs to the glucose derivatives. We synthesized glucosamine triazol derivatives $\mathbf{4 - 1 9}$, which include the typical functional groups such as amino (4), hydroxyl (5-10), aryl (12-13), and alkyl groups (14-16) by coupling with the corresponding monoalkyne. Compounds $\mathbf{5}$ and $\mathbf{1 2}$ have been reported as O-GlcNAcase inhibitors. ${ }^{33 b, c}$ The dimeric compounds $\mathbf{1 7 - 1 9}$ with four to six methylene linkers were synthesized using dialkyne starting materials. These compounds were then tested for their gelation properties in several solvents. The results are shown in Table 1. 

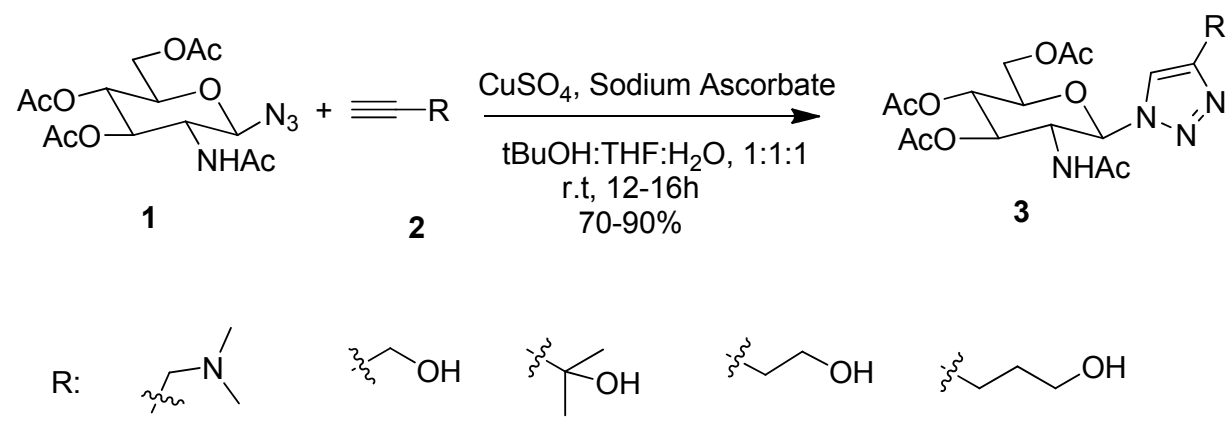
4, $81 \%$
5, $82 \%$
6, $87 \%$
7, $85 \%$
8, $82 \%$<smiles>CCCCCCCCCCCO</smiles>

9, $86 \%$

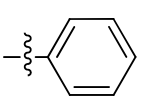

$12,82 \%$
$10,82 \%$

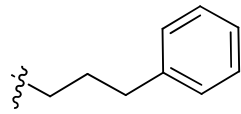

$13,77 \%$<smiles>CCCCCCCCCC(=O)O</smiles>

$11,81 \%$

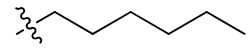

$14,87 \%$

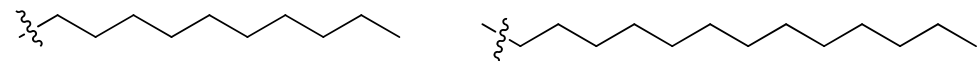

$15,84 \%$

$16,76 \%$

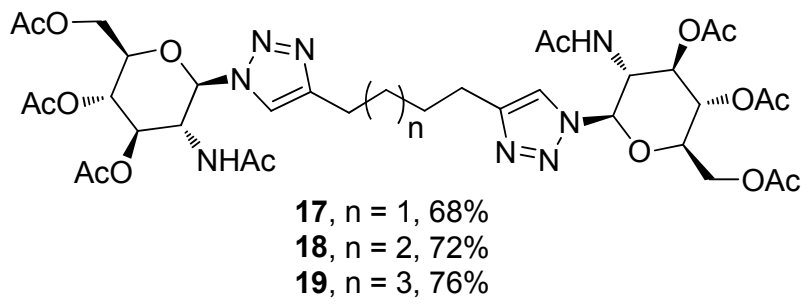

Scheme 1. Synthesis of D-glucosamine triazole derivatives by the CuAAC 'click' reaction.

From Table 1, we can see that a majority of the compounds were able to form gels in at least one of the tested solvents. The compounds with less polar substituents tend to be more effective gelators. At $20 \mathrm{mg} / \mathrm{mL}$, all of the compounds were insoluble in hexane. Four compounds were able to gelate toluene, the short chain alcohol derivatives $\mathbf{8}$ and $\mathbf{9}$, the acid 11, and aryl analog $\mathbf{1 2}$. A majority of the compounds were soluble in ethanol and isopropanol, only two compounds 
were able to form gels in the tested alcohols. The dimer $\mathbf{1 7}$ formed a gel in isopropanol and the long alkyl chain derivative $\mathbf{1 6}$ formed a gel in ethanol. Though they are not effective gelators for pure alcohols, we were pleased to find that many of the compounds were efficient gelators for aqueous mixtures of ethanol or DMSO, and seven compounds were also effective hydrogelators.

The compounds with short chain amino group 4 and alcohols 5-7 are soluble in all tested solvents at $20 \mathrm{mg} / \mathrm{mL}$. But with increasing methylene groups in the molecule, they become effective gelators. Compounds 8 and 9 were able to form transparent gels in toluene at $0.2 \mathrm{wt} \%$ and $0.17 \mathrm{wt} \%$, respectively. The long alkyl alcohol $\mathbf{1 0}$ is an effective gelator for water and DMSO water mixture, while the long fatty acid derivative $\mathbf{1 1}$ is a versatile gelator for organic solvents, aqueous ethanol and DMSO, and water. The compounds containing nonpolar long alkyl chain (14-16) or aryl groups (12-13) are effective gelators for polar solvents and water as well. When R group contains non-polar functional groups such as in $\mathbf{1 2 - 1 6}$, typically the products are able to form gels in the aqueous mixtures. The dimeric analogs with longer spacers are more effective towards the gelation of these solvents. For instance, compound $\mathbf{1 9}$ was much more efficient in comparison to compound $\mathbf{1 7}$ with shorter spacer. In comparison to the analogues from the D-glucose series, the D-glucosamine derivatives are much more efficient as hydrogelators. 
Table 1. Gelation test results for the library compounds in several solvents.

\begin{tabular}{|c|c|c|c|c|c|c|c|c|c|}
\hline $\begin{array}{c}\text { Compoun } \\
\text { d }\end{array}$ & Hexane & Toluene & i-PrOH & $\mathrm{EtOH}$ & $\begin{array}{c}\text { EtOH: } \mathrm{H}_{2} \mathrm{O} \\
(1: 1)\end{array}$ & $\begin{array}{c}\text { EtOH: } \\
\mathrm{H}_{2} \mathrm{O}(1: 2)\end{array}$ & $\begin{array}{c}\text { DMSO: } \\
\mathrm{H}_{2} \mathrm{O}(1: 1)\end{array}$ & $\begin{array}{c}\text { DMSO: } \\
\mathrm{H}_{2} \mathrm{O}(1: 2)\end{array}$ & $\mathrm{H}_{2} \mathrm{O}$ \\
\hline 4 & I & $\mathrm{S}$ & $\mathrm{S}$ & $\mathrm{S}$ & $\mathrm{S}$ & $\mathrm{S}$ & $\mathrm{S}$ & $\mathrm{S}$ & $\mathrm{S}$ \\
\hline 5 & I & $\mathrm{S}$ & $\mathrm{S}$ & $\mathrm{S}$ & S & S & S & S & S \\
\hline 6 & I & S & S & S & S & S & S & $\mathrm{S}$ & $\mathrm{S}$ \\
\hline 7 & I & S & $\mathrm{S}$ & $\mathrm{S}$ & S & S & S & S & S \\
\hline 8 & I & G 2.0 & $\mathrm{~S}$ & S & $\mathrm{S}$ & S & $\mathrm{S}$ & $\mathrm{S}$ & $\mathrm{S}$ \\
\hline 9 & I & G 1.7 & $\mathrm{~S}$ & $\mathrm{~S}$ & $\mathrm{~S}$ & $\mathrm{~S}$ & $\mathrm{~S}$ & S & S \\
\hline 10 & I & I & $\mathrm{P}$ & S & $\mathrm{P}$ & $\mathrm{P}$ & $\mathrm{P}$ & G 4.0 & G 2.8 \\
\hline 11 & I & G 2.8 & $\mathrm{~S}$ & S & G 10.0 & G 10.0 & S & G 20.0 & G 4.0 \\
\hline 12 & I & G 5.0 & S & $\mathrm{P}$ & $\mathrm{P}$ & G 6.7 & G 10.0 & G 2.2 & $\mathrm{P}$ \\
\hline 13 & I & S & $\mathrm{S}$ & $\mathrm{S}$ & G 2.5 & G 2.8 & G 10.0 & G 2.2 & G 2.2 \\
\hline 14 & I & S & S & $\mathrm{S}$ & G 3.3 & G 6.6 & G 2.2 & G 1.9 & G 2.0 \\
\hline 15 & I & $\mathrm{S}$ & $\mathrm{S}$ & $\mathrm{S}$ & G 2.2 & G 6.6 & G 2.0 & G 1.7 & G 10.0 \\
\hline 16 & I & I & $\mathrm{P}$ & G 10.0 & G 5.0 & G 5.0 & G 2.5 & G 3.3 & $\mathrm{P}$ \\
\hline 17 & I & $\mathrm{S}$ & G 20.0 & $\mathrm{P}$ & $\mathrm{P}$ & $\mathrm{P}$ & $\mathrm{P}$ & $\mathrm{P}$ & I \\
\hline 18 & I & I & $\mathrm{P}$ & S & PG 20.0 & PG 20.0 & PG 20.0 & G 10.0 & G 10.0 \\
\hline 19 & I & I & PG 20.0 & PG 20.0 & PG 20.0 & PG 20.0 & G 10.0 & G 10.0 & G 5.0 \\
\hline
\end{tabular}

$\mathrm{G}$, gel at room temperature, the numbers are the corresponding minimum gelation concentrations (MGCs) in mg/mL; PG, partial gel or unstable gel; I, insoluble; C, crystallize or precipitate; S, soluble at $\sim 20 \mathrm{mg} / \mathrm{mL}$. 
The morphologies of several gels were then studied using optical microscope. Fig. 1 shows the optical micrographs of the gels formed by compounds $10,13,14$, and 15 . These images are taken while the gels still contain solvents. As a general feature, these various gelators formed selfassembled fibrous networks. Compound $\mathbf{1 0}$ formed a translucent gel in water at $2.8 \mathrm{mg} / \mathrm{mL}$, the morphology (Fig. 1a) shows continuous fibrous assemblies. The phenyl derivative $\mathbf{1 3}$ formed a translucent gel in ethanol water mixture, the assemblies are composed of many long, curvy, thin and uniform fibrous networks (Fig. 1b). The hydrogel formed by compound 14 also exhibits selfassembled fibrous features and the fibers or tubules have larger diameters (Fig. 1c, d); the compound $\mathbf{1 4}$ formed gel in ethanol water mixture and showed uniform fibers or tubules, these fibers appeared to have similar widths and are less branched (Fig. 1e), and lastly the hydrogel formed by compound $\mathbf{1 5}$ showed thin fibrous assemblies, and some fibers seem to merge to form thicker cylindrical tubules (Fig. 1f). 

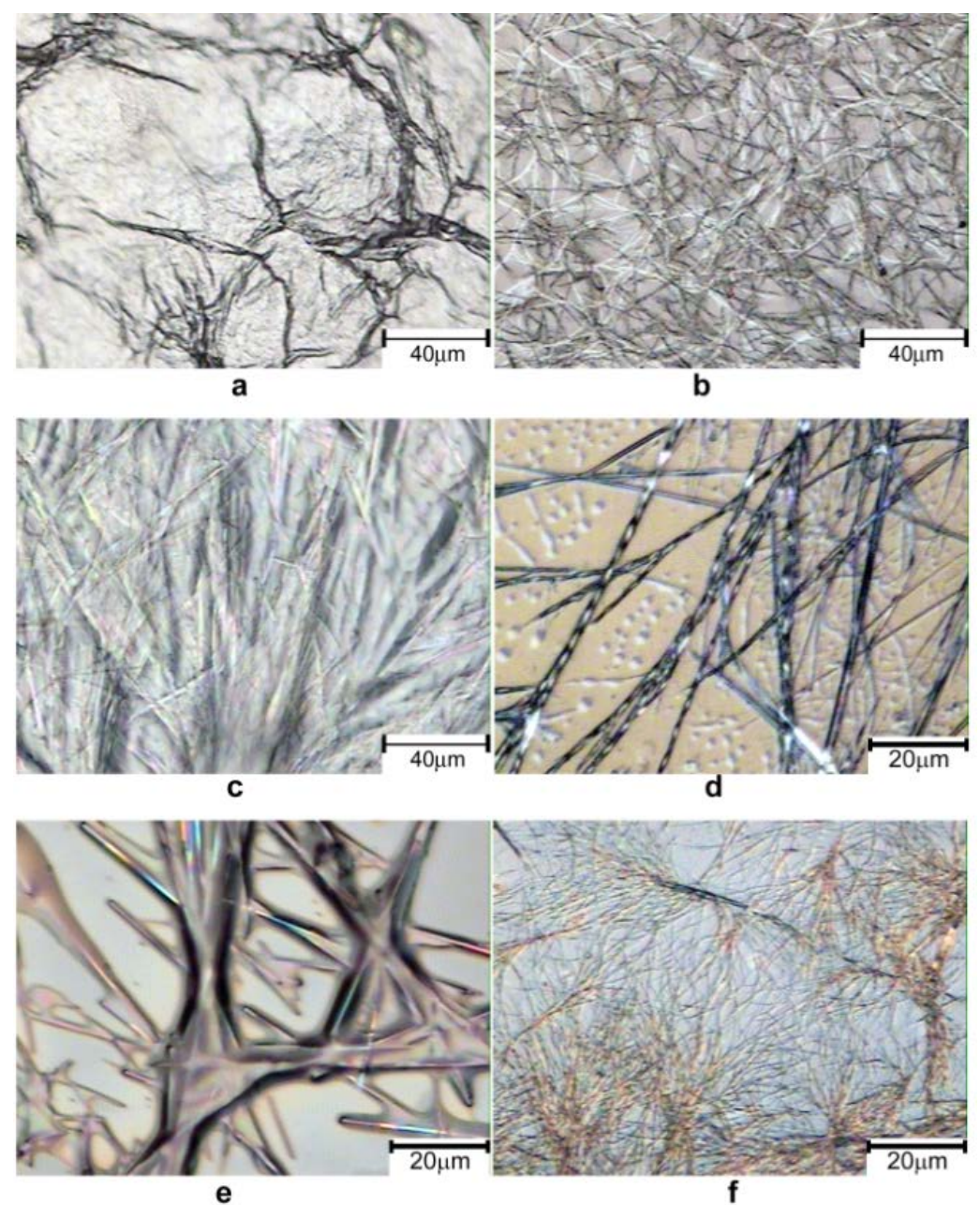

Fig. 1 Optical micrographs of the gels formed by several compounds: a) compound $\mathbf{1 0}$ in $\mathrm{H}_{2} \mathrm{O}$ $2.8 \mathrm{mg} / \mathrm{mL}$; b) compound $\mathbf{1 3}$ in $\mathrm{EtOH} / \mathrm{H}_{2} \mathrm{O}(1: 2)$ at $2.8 \mathrm{mg} / \mathrm{mL}$; c-d) compound $\mathbf{1 4}$ in $\mathrm{H}_{2} \mathrm{O}$ at 2.0 $\mathrm{mg} / \mathrm{mL}$; e) compound 14 in in $\mathrm{EtOH} / \mathrm{H}_{2} \mathrm{O}(1: 2)$ at $6.6 \mathrm{mg} / \mathrm{mL}$; f) compound 15 in $\mathrm{EtOH} / \mathrm{H}_{2} \mathrm{O}$ $(1: 2)$ at $2.0 \mathrm{mg} / \mathrm{mL}$.

We also studied the dynamic rheology properties for three compoungs. In Fig. 2 the dynamic moduli $\mathrm{G}^{\prime}$ and $\mathrm{G}^{\prime \prime}$ are shown as a function of angular frequency $\omega$ at their minimum gelation concentrations for compounds 10, 13 and 15. As shown in Fig. 2, the storage modulus $G^{\prime}$ is greater than the Loss modulus $G^{\prime \prime}$ for all these compounds. The fact that $G^{\prime}$ is greater than $G^{\prime \prime}$ is 
an indication that the gels are elastic semisolid.

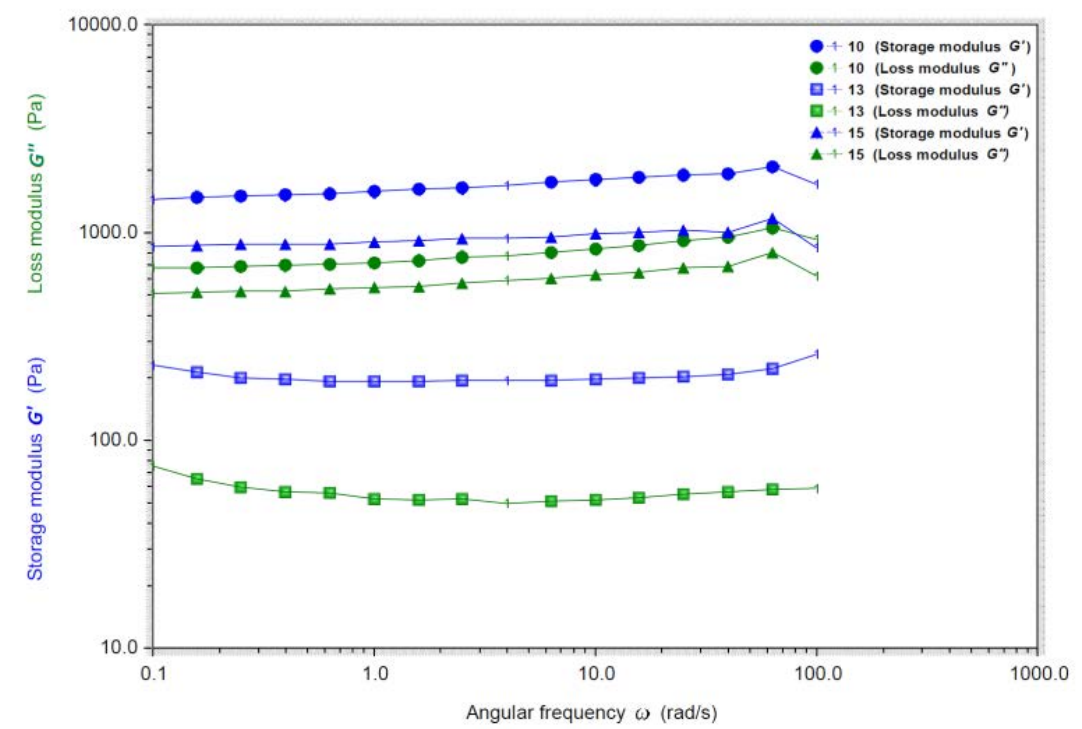

Fig. 2. Rheological properties of the gels formed by compounds $\mathbf{1 0}\left(\mathrm{H}_{2} \mathrm{O}, 2.8 \mathrm{mg} / \mathrm{mL}\right), \mathbf{1 3}\left(\mathrm{H}_{2} \mathrm{O}\right.$, $2.2 \mathrm{mg} / \mathrm{mL}$ ) and 15 (DMSO: $\mathrm{H}_{2} \mathrm{O}, 1: 1,2.0 \mathrm{mg} / \mathrm{mL}$ ) at their minimum gelation concentration.

\section{Conclusions}

In summary, we have synthesized a series of $\mathrm{N}$-acetyl glucosamine based triazole derivatives and studied their self-assembling properties. Among the analogues studied, we found that the compounds containing long aliphatic spacers are generally effective low molecular weight gelators. More importantly, seven efficient hydrogleators have also been obtained; many of them were able to form hydrogels at concentrations lower than $1.0 \mathrm{wt} \%$. These results indicate that peracetylated D-glucosamine triazole analogs are very effective small molecular gelators. The glucosamine based hydrogels may find potential applications in biomedicine and as advanced materials. 


\section{Acknowledgement}

We are grateful for financial support by a grant from NSF CHE 1153129 and Old Dominion University.

\section{References and Notes}

1. (a) Terech, P.; Weiss, R. G. Chem. Rev. 1997, 97, 3133-3159. (b) George, M.; Weiss, R. G. Acc. Chem. Res. 2006, 39, 489-497. (c) Babu, S. S.; Praveen, V. K.; Ajayaghosh, A. Chem. Rev. 2014, 114, 1973-2129.

2. (a) Estroff and, L. A.; Hamilton, A. D. Chem. Rev. 2004, 104, 1201-1217. (b) Yang, Z.; Liang, G.; Xu, B. Acc. Chem. Res. 2008, 41, 315-326.

3. (a) Dastidar, P. Chem. Soc. Rev. 2008, 37, 2699-2715. (b) Buerkle, L. E.; Rowan, S. J. Chem. Soc. Rev. 2012, 41, 6089-6102.

4. (a) Tomasini, C.; Castellucci, N. Chem. Soc. Rev. 2013, 42, 156-172. (b) de Loos, M.; Feringa, B. L.; Van Esch, J. H. Eur. J. Org. Chem. 2005, 17, 3615-3631.

5. (a) Hoffman, A. S. Adv. Drug Deliver. Rev. 2002, 54, 3-12. (b) Vintiloiu, A.; Leroux, J. -C. J. Control. Release. 2008, 125, 179-192. (b) Hirst, A. R.; Escuder, B.; Miravet, J. F.; Smith, D. K. Angew. Chem. Int. Ed. 2008, 47, 8002-8018.

6. (a) Koshi, Y.; Nakata, E.; Yamane, H.; Hamachi, I. J. Am. Chem. Soc. 2006, 128, 1041310422. (b) Kiyonaka, S.; Sada, K.; Yoshimura, I.; Shinkai, S.; Kato, N.; Hamachi, I. Nat. Mater. 2004, 3, 58-64. (c) Matsumoto, S.; Yamaguchi, S.; Ueno, S.; Komatsu, H.; 
Ikeda, M.; Ishizuka, K.; Iko, Y.; Tabata, K. V.; Aoki, H.; Ito, S.; Noji, H.; Hamachi, I. Chem. Eur. J. 2008, 14, 3977-3986.

7. Yang, Z.; Liang, G.; Guo, Z.; Guo, Z.; Xu, B. Angew. Chem. Intl. Ed. 2007, 46, 82168219.

8. Yang, C.; Li, D.; Liu, Z.; Hong, G.; Zhang, J.; Kong, D.; Yang, Z. J. Phys. Chem. B. 2012, 116, 633-638.

9. Ray, S.; Das, A. K.; Banerjee, A. Chem. Mater. 2007, 19, 1633-1639.

10. Wang, H.; Yang, Z. Nanoscale 2012, 4, 5259-5267.

11. Cao, S.; Fu, X.; Wang, N.; Wang, H.; Yang, Y. Int. J. Pharm. 2008, 357, 95-99.

12. (a) Wang, G.; Hamilton, A. D. Chem. Commun. 2003, 311-312. (b) Wang, G.; Hamilton, A. D. Chem. Eur. J. 2002, 8, 1954-1961.

13. Suzuki, M.; Yumoto, M.; Kimura, M.; Shirai, H.; Hanabusa, K. Chem. Commun. 2002, $8,884-885$.

14. Geisler, I. M.; Schneider, J. P. Adv. Funct. Mater. 2012, 22, 529-537.

15. Mitra, R. N.; Das, D.; Roy, S.; Das, P. K. J. Phys. Chem. 2007, 111, 14107-14113.

16. Mangunuru, H. P. R.; Yang, H.; Wang, G. Chem. Commun. 2013, 49, 4489-4491.

17. Roy, S.; Dasgupta, A.; Das, P. K. Langmuir, 2007, 23, 11769-11776.

18. Wang, Y.; Zhang, Z.; Xu, L.; Li, X.; Chen, H. Colloids Surf. B: Biointerfaces. 2013, 104, 163-168.

19. Roy, S.; Kumar, D.; Panigrahi, S.; Basak, D.; Banerjee, A. RSC Advances. 2012, 29, 11053-11060. 
20. (a) Yang, Z.; Liang, G.; Xu, B. Soft Matter. 2007, 3, 515-520. (b) Rodríguez-Llansola, F.; Escuder, B.; Hamley, I. W.; Hayes, W.; Miravet, J. F. Soft Matter 2012, 8, 88658872.

21. Lagadecand, C. A.; David, D. K. Chem. Commun. 2012, 48, 7817-7819.

22. Maslovskis, A.; Tirelli, N.; Saiani, A.; Miller, A. F. Soft Matter 2011, 7, 6025-6033.

23. Banwell, E.; Abelardo, E. S.; Adams, D. J.; Birchall, M. A.; Corrigan, A.; Donald, A. M.; Kirkland, M.; Serpell, L. C.; Butler, M. F.; Woolfson, D. N. Nat. Mater. 2009, 8, 596-600.

24. (a) Li, X.; Du, X.; Li, J.; Gao, Y.; Pan, Y.; Shi, J.; Zhou, N.; Xu, B. Langmuir. 2012, 28, 13512-13517. (b) Nandi, S.; Altenbach, H.; Jakob, B.; Lange, K.; Ihizane, R.; Schneider, M. P.; Gün, Ü.; Mayer, A. Org. Lett. 2012, 14, 3826-3829.

25. (a) Wang, G.; Sharma, V.; Cheuk, S.; Williams, K.; Dakessian, L.; Thorton, Z. Carbohyd. Res. 2006, 341, 705-716. (b) Cheuk, S.; Stevens, E.; Wang, G. Carbohyd. Res. 2009, 344, 417-425.

26. (a) Nie, X.; Wang, G. J. Org. Chem. 2006, 71, 4734-4741. (b) Wang, G.; Yang, H.; Cheuk, S.; Coleman, S. Beilstein J. Org. Chem. 2011, 7, 234-242.

27. Wang, G.; Cheuk, S.; Yang, H.; Goyal, N.; Reddy, P. V. N.; Hopkinson, B. Langmuir. 2009, 25, 8696-8705.

28. Cheuk, S.; Goyal, N.; Wang, G. Tetrahedron 2010, 66, 5962-5971.

29. Mangunuru, H. P. R.; Jayasudhan Reddy.Y.; Liu, D.; Wang, G. Tetrahedron Lett. 2015, $56,82-85$. 
30. (a) Clemente, M. J.; Fitremann, J. ; Mauzac, M.; Serrano, J. L.; Oriol, L. Langmuir. 2011, 27, 15236-15247. (b) Clemente, M. J.; Romero, P.; Serrano, J. L.; Fitremann, J.; Oriol, L. Chem. Mater. 2012, 24, 3847-3858.

31. (a) Kolb, H. C.; Finn, M. G.; Sharpless, K. B. Angew. Chem., Int. Ed. 2001, 40, 20042021. (b) Meldal, M.; Tornoe, C. W. Chem. Rev. 2008, 108, 2952-3015. (c) Dedola, S.; A.Nepogodiev, S.; Field, R. A. Org. Biomol. Chem. 2007, 5, 1006-1017. (d) Moses, J.E.; Moorhouse, A. D. Chem. Soc. Rev. 2007, 36, 1249-1262. (e) Thirumurugan, P.; Matosiuk, D.; Jozwiak, K. Chem. Rev. 2013, 113, 4905-4979.

32. (a) Dondoni, A. Chem. Asian J. 2007, 2, 700-708. (b) Kushwaha, D.; Dwivedi, P.; Kuanar, S. K.; Tiwari, V. K. Curr. Org. Syn. 2013, 10, 90-135.

33. (a) Chittaboina, S.; Xie, F.; Wang, Q. Tetrahedron Lett. 2005, 46, 2331-2336. (b) Li, T.; Guo, L.; Zhang, Y.; Wang, J.; Li, Z.; Zhang, Z.; Li, L.; Lin, J.; Zhao, W.; Li, J.; Wang, P. G. Carbohyd. Res. 2011, 346, 1083-1092. (c) Bokor, E.; Koppany, C.; Gonda, Z.; Novak, Z.; Somak, L. Carbohyd. Res. 2012, 351, 42-48.

34. D1'az, D. D.; Rajagopal, K.; Strable, E.; Schneider, J.; Finn, M. G. J. Am. Chem. Soc. 2006, 128, 6056-6057.

35. Bhalla, V.; Singh, H.; Kumar, M.; Prasad, S. K. Langmuir. 2011, 27, 15275-15281.

36. Hemamalinia, A.; Das, T. M. New J. Chem. 2013, 37, 2419-2425. 